\title{
Whom to ask for help? Children's developing understanding of other people's action capabilities
}

\author{
Markus Paulus $\cdot$ Chris Moore
}

Received: 10 December 2010 / Accepted: 1 April 2011 / Published online: 21 April 2011

(C) The Author(s) 2011. This article is published with open access at Springerlink.com

\begin{abstract}
We often rely on other people's help to accomplish tasks and to attain goals. People, however, differ in their physical action capabilities. Some persons are therefore better able to provide help than others. We investigated 2.5-, 3.5-, and 5-year-old children's ability to take other person's action capabilities in a helping situation into account. To this end, they observed a protagonist who needed the help of friends to accomplish several tasks. For each task, two friends were available, but only one was physically able to provide the help. Children were asked to indicate, which partner the protagonist will ask for help. Our results showed a developmental effect with children in the older two groups performing significantly better than those in the youngest group. Additionally, we found evidence that the 5-year-olds outperformed the younger age groups in their ability to justify their choice. Our findings thus suggest that children's ability to consider others' physical action capabilities in helping situations develops around 3 years of age. The results are interpreted in terms of children's ability to perceive others' affordances. The implication of these findings for theories on the development of action understanding and joint action are discussed.
\end{abstract}

Keywords Prosocial behavior · Development - Helping · Action capability $\cdot$ Joint action

M. Paulus ( $\square)$

Donders Institute for Brain, Cognition and Behaviour, Radboud University Nijmegen, Nijmegen, The Netherlands e-mail:m.paulus@donders.ru.nl

C. Moore

Dalhousie University, Halifax, NS, Canada

\section{Introduction}

Imagine searching around for a lost object. Eventually you see it on the top of a high cupboard, but it is too high for you to reach. Luckily, there are some people around you whom you could ask for help. Clearly, as you want to retrieve an object from a high cupboard, you would ask the taller person to help you, but not the smaller person. As this example nicely illustrates, the ability to correctly judge other people's action capabilities plays an important role in our social life, not only in collaborative but also in competitive situations. Whereas adults indubitably possess a certain proficiency in taking others' action capabilities into account when looking for help, almost nothing is known about the development of this ability in childhood.

Generally, young children rely on other persons' help to a great extent. It is well established that young children show social referencing behavior when they are uncertain about situations (e.g., Moore 2006; Walden and Ogan 1988), and they seek information (e.g., Baldwin and Moses 1996) and help from others to accomplish tasks and attain goals (e.g., Newman 2000; Puustinen 1998). However, as illustrated by the presented example, proper functioning in a dynamic social environment requires sophisticated knowledge about with whom to interact to attain a goal and whom to ask for help or for information in certain situations.

Interestingly, recent research on children's selective social learning has indicated that preschoolers use information about the success of a person's past actions (Birch et al. 2008), or the past accuracy of information provided by a person (Corriveau and Harris 2009; Pasquini et al. 2007), to decide on whom to rely when different persons offer conflicting information. For example, it has been shown that 4- but not 3-year-old children selectively trusted 
a previously correct person in a word-learning situation, when he gave different information than a previously incorrect or ignorant speaker (Koenig and Harris 2005). Interestingly, a person's past accuracy seems to be more important than an actor's age as preschoolers rely more on a previously accurate person than on an older person (Jaswal and Neely 2006). Furthermore, selective learning is not restricted to the acquisition of novel words. Rakoczy and colleagues (Rakoczy et al. 2009) showed that 4-year-old children also preferred to learn novel rules (i.e., normative appropriate actions) from a previously reliable model compared with an unreliable one.

The reviewed literature provides evidence for preschool children's selective reliance on persons when acquiring novel knowledge. Whereas these studies have provided important insights, research has neglected the domain of others' physical action capabilities. Research with adults has shown that humans are quite proficient in estimating other people's action capabilities (e.g., Stoffregen et al. 1999), and subsequent research, informed by Ecological Psychology (e.g., Marsh et al. 2009; Richardson et al. 2008), has suggested that such an estimation is based on the detection of action-relevant properties of other agents in relation to their environment (i.e., action affordances; Ramenzoni et al. 2008). Knowledge about the development of this ability is of relevance for developmental psychologists as it provides insight into children's ability to select appropriate persons when seeking help (e.g., when we need to retrieve something from a high cupboard). Furthermore, this domain is of relevance for researchers interested in the development of the ability to engage successfully in joint action because efficient interaction with others relies on an appropriate evaluation of their action capabilities (Sebanz et al. 2006).

The present study investigated the development of children's understanding of others' action capabilities. To be able to examine systematically children's evaluations of other's action capabilities across a number of different person characteristics (e.g., such as strength or height), we decided to employ a third-person helping task in which dolls represented the actor as well as possible helpers in a number of different situations (for comparable third-person approaches see, for example, Fawcett and Markson 2010a, b; Olson and Spelke 2008; Vaish et al. 2011). In particular, children were introduced to a protagonist who needed the help of others in five tasks. For example, one task required retrieving a displayed item, while another task involved carrying a heavy object. In every situation, two friends of the protagonist were present. In each case, only one of the friends was able to provide the help as only he/she was, for example, tall or strong enough.

To examine children's ability to choose the adequate person for help, we assessed their judgments of which of the friends the actor would ask for help. Furthermore, chil- dren were asked to justify their choice. A comparison between both measures would be informative with respect to the possible social-cognitive mechanisms that underlie children's developing ability to evaluate others' action capabilities. If children were able to choose correctly the adequate helper before they were able to justify their choice, this would suggest that their ability to evaluate others' action capabilities is initially more practical form of knowledge that over developmental time becomes explicated in conceptual or discursive knowledge (KarmiloffSmith 1992; for detailed epistemological analyses of this account see Brandom 1994; Habermas 1985). However, if there was no developmental lag between the two measures, this would indicate that even at its developmental origin, this knowledge is of conceptual nature (for a similar discussion concerning the cognitive mechanisms behind children's selective learning from other people see Koenig and Jaswal 2011; Lucas and Lewis 2010). As it has been suggested that children from 3 years on are able to estimate other people's reachability space (Rochat 1995), we investigated 2.5-, 3.5-, and 5-year-old children.

\section{Method}

Participants

The final sample of the study consisted of 36 children, including twelve 2.5-year-old children (range: 2 years, 5.8 months -2 years, and 11.3 months; 6 boys), twelve 3.5 year-old children (range: 3 years, 5.2 months -3 years, and 10.7 months; 7 boys), and twelve 5-year-old children (range: 4 years, 6.2 months -5 years, and 4.2 months; 7 boys). The participants were recruited from a database of parents who volunteered to participate in psychological studies, all being native English speakers from heterogeneous socioeconomic background in Nova Scotia, Canada. Informed consent for participation was given by the children's parents. The families received a certificate for their visit.

\section{Tasks and materials}

Children were presented with ten dolls over the course of the five tasks (see Fig. 1). One doll represented the protagonist (Piglet). In every task, two dolls represented friends of Piglet. The tasks were performed by one experimenter and varied in the type of problem that the protagonist encountered and the type of action capability required. Action capability was varied between the two dolls that represented Piglet's friends. Every task started with Piglet appearing in the scene, greeting his friends, and subsequently either trying, but failing to perform an action or announcing that he was not able to perform the action. 


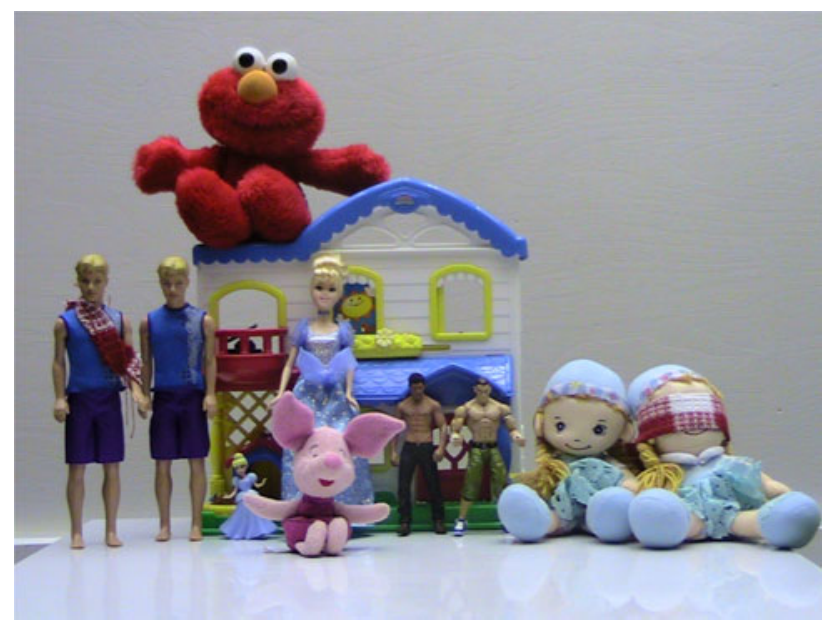

Fig. 1 The figure displays the stimuli used in the experiment. The doll in the front shows the main protagonist Piglet. The dolls behind Piglet show (from left to right) the two male dolls used in the basket task, the two princesses used in the balcony and the dog's house task, the two male dolls used in the wall task, and the two girls used in the letter task. The doll on the top of the toy house is Elmo who has been employed for the balcony and the dog's house task

After admitting that he could not perform the action himself, he articulated that he could ask one of his friends for help. He subsequently approached his friends. The experimenter asked the child to show him which of his two friends Piglet would ask for help, using the same test question: "What do you think: Which of his friends is Piglet going to ask for help?" If the child did not react, the question was repeated in another wording: "Who is Piglet going to ask for help?" If the child made the correct choice, he or she was further asked to justify why Piglet would ask this friend and not the other. The order of tasks was balanced among participants with the exception of the balcony task and the dog's house task; as both tasks involved the same dolls, they were always presented after each other.

\section{The balcony task (Out of reach)}

A tall and a small princess were standing in front of a toy house. Piglet entered the scene with two objects in his hand. He greeted the princesses and started playing with his objects. Suddenly, another actor (Elmo) showed up, took one of the objects, and put it on the balcony of the toy house. Piglet expressed sadness that the object was gone and tried to get it back. He reached for it, but was not tall enough to get it. He admitted that he could not get it and might need the help of one of his friends.

\section{The dog's house task (Small hole)}

The same princesses were standing in front of the house. Piglet continued to play with his items. Elmo showed up again, took the other object, and put it into the dog's house. Piglet expressed sadness that the object was gone and tried to get it back. He tried to get into the dog's house, but was not small enough to enter it. He admitted that he could not get his object and might need the help of one of his friends.

\section{The basket task (Two hands)}

Two men were standing in front of the house. The dolls were identical apart from the fact that one had a sling around his arm and neck as if he had broken his arm. Piglet entered by jumping onto the table carrying a basket with two handles. He greeted the men and asked them how they have been doing. Whereas one expressed that he was enjoying the day, the other said that he had broken his arm and cannot do anything with it. Piglet then picked up the basket again, taking each handle with one hand while verbalizing that he needed one hand for each handle. He carried it around, but stopped after a couple of seconds and announced that the basket is very heavy. He admitted that he could not carry it and might need some help from one of his friends.

\section{The letter task (Reading task)}

Two girls were standing in front of the house. The dolls were identical besides the fact that one had a blindfold over her eyes. Piglet entered the table with a piece of paper in his hand. He greeted the girls and asked what they were doing. The girl who was not blindfolded announced that she had blindfolded her sister to play a game with her. She danced around her sister and asked her, if she could see her. The blindfolded sister responded that she could not. Thereupon, the girl who was not blindfolded asked Piglet, if he wanted to join, but Piglet declined. He told the girls that he had just received a letter from his mother and would like to know what is written on this letter. He admitted that he could not read it and might need the help of one of his friends.

\section{The wall task (Heavy object)}

Two men were standing in front of the house. Both dolls showed shirtless men, of which one was clearly more muscular than the other. Piglet entered the scene. He greeted the men and asked them how they have been doing. The less muscular man responded that he was enjoying the day, whereas the other responded that he has recently won a prize for being the strongest man in Canada and invited Piglet to feel his muscles. Piglet felt his muscles and then announced that he has to get some work done, in particular, that he has to move a wall. When repeatedly trying to move it, the wall moved only slightly. Piglet admitted that he could not move it and might need some help from one of his friends. 
Fig. 2 a Shows the average choice value (i.e., average correct choice) for the 2.5-, 3.5-, and 5-year-old children. Error bars indicate standard error of the means. The bold horizontal line emphasizes the $50 \%$ value (i.e., chance performance). b Shows the average justification value for the 2.5-, 3.5-, and 5-year-old children. Error bars indicate standard error of the means. c Gives a more detailed overview over the different categories of answers provided by the 2.5-, 3.5-, and 5-year-old children in the justification question. The light gray bar represents the performances of the 2.5-year-old children, the intermediate gray bar represents the performances of the 3.5-year-old children, and the dark gray bar represents the performances of the 5-year-old children
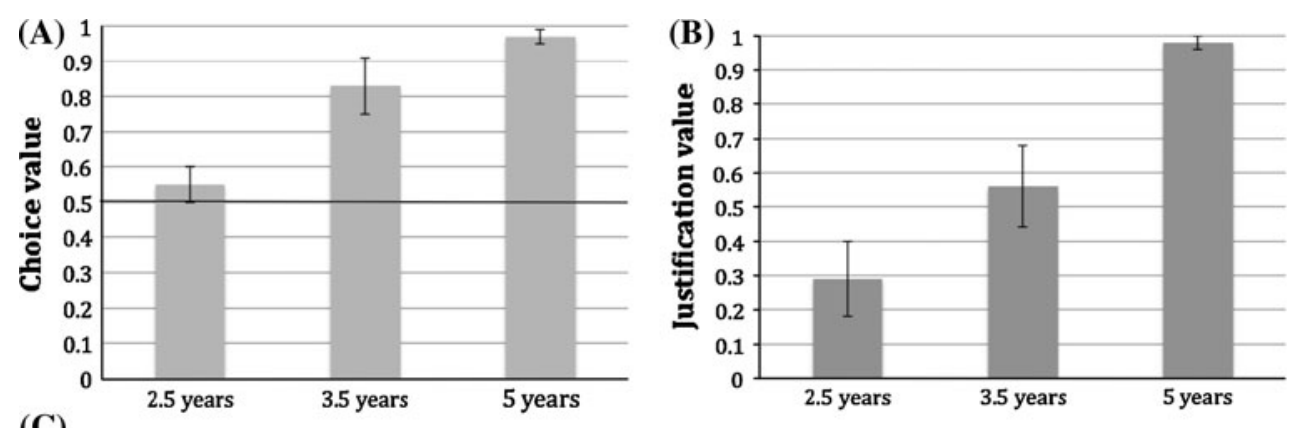

(C)

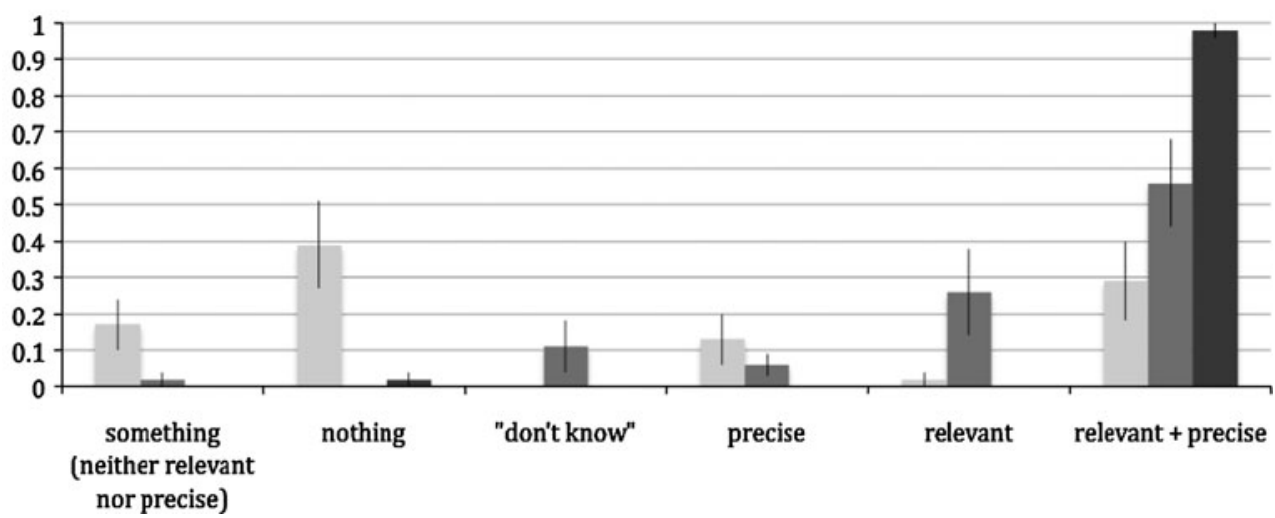

person characteristic (e.g., when in the balcony task, the participant answered: "this doll is taller than the other", "she is tall enough"). If the child's answer was not appropriate, the answer was further coded as being only relevant but not precise (e.g., "because he needs help", "because she can get the candle"), only precise but not relevant (e.g., "because she is a princess", "because he wears pants"), explicit statement of ignorance (e.g., "I don't know"), something else (e.g., "Look. There."), or no answer given (see Fig. 2c). A justification value was defined for each participant based on the proportion of trials in which a relevant and precise answer was given. An interrater reliability analysis using the Kappa statistic was performed to determine consistency among raters. The analysis yielded a good level of agreement $(\kappa=0.80, P<0.001)$. Data were analyzed employing an ANOVA with the between-subjects factor age group $(2.5,3.5$, and 5 years).

\section{Results}

Figure 2a displays the averages of the choice values per age group. A preliminary analysis yielded no significant differences between tasks (Cochran's Q $(4)=2.250, P=0.69$; see Table 1). The analysis yielded a significant effect of age group, $F(2,33)=15.152, P<0.001, \eta_{\mathrm{p}}^{2}=0.48$. Post-hoc $t$ tests revealed that the performances of the 2.5-year-olds differed significantly from the 3.5- and 5-year-olds, $t(22)=3.081, \quad P<0.01$ and $t(22)=7.601, \quad P<0.001$, respectively, whereas no significant differences were found 
Table 1 Displays the results by age group (rows) and task (columns)

Each cell shows the average performance of children of a particular age group in a task

\begin{tabular}{lccccc}
\hline & $\begin{array}{l}\text { Balcony } \\
\text { task }(\%)\end{array}$ & $\begin{array}{l}\text { Dog's house } \\
\text { task }(\%)\end{array}$ & $\begin{array}{l}\text { Basket } \\
\text { task }(\%)\end{array}$ & $\begin{array}{l}\text { Letter } \\
\text { task }(\%)\end{array}$ & $\begin{array}{l}\text { Wall } \\
\text { task }(\%)\end{array}$ \\
\hline $\begin{array}{l}2.5 \text { years } \\
\text { 3.5 years }\end{array}$ & 33 & 67 & 67 & 58 & 50 \\
5 years & 83 & 67 & 83 & 92 & 92 \\
\hline
\end{tabular}

between these age groups, $t(22)=1.658, P=0.11$. The $t$ tests against chance level showed that the performances of the 3.5-year-olds, $t(11)=4.318, P<0.005)$ and of the 5year-olds differed from chance, $t(11)=20.765, P<0.001$, but the performance of the 2.5 -year-olds ${ }^{1}$ did not $t(11)=1.000, P=0.34$.

Next, we analyzed the justification values (i.e., the frequency of relevant and precise justifications in trials in which participants had chosen the correct doll). The analysis of the justification values revealed a significant effect of age group, $F(2,33)=13.054, P<0.001, \eta_{\mathrm{p}}^{2}=0.44$. Posthoc $t$ tests showed that the performance of the 5-year-olds $(\mathrm{M}=97.9 \%, \mathrm{SD}=7.2)$ differed significantly from the 3.5and 2.5-year-olds $(\mathrm{M}=56.1 \%, \mathrm{SD}=41.1$, and $\mathrm{M}=29.2 \%$, $\mathrm{SD}=39.6, \quad$ respectively), $t(22)=3.476, \quad P<0.01$, and $t(22)=5.910, P<0.001$, respectively, whereas no significant differences was found between the latter age groups, $t(22)=1.634, P=0.12$.

\section{Discussion}

The goal of this study was to assess the development of children's ability to take other person's action capabilities in a helping situation into account. To this end, 2.5-, 3.5-, and 5-year-old children observed a protagonist who needed the help of friends to accomplish several tasks. Typically, only one of the friends was physically able to provide the help. Our results showed a significant developmental effect with children in the two older groups performing significantly better than those in the youngest group. Furthermore, children in the two older groups chose the appropriate character at levels well above chance, whereas the performance of the younger children did not differ from chance. We may infer, therefore, that the 3.5- and 5-year-old, but not the 2.5year-old children were able to choose the appropriate doll for help. We interpret our findings as evidence that chil-

\footnotetext{
${ }^{1}$ To ensure that 2.5 -year-olds' failure was not merely due to the verbal demands of the task, we randomly asked eight participants in one of the tasks, in which they failed to choose the appropriate doll, to show what the chosen doll has to do to help Piglet. Seven out of the eight participants correctly initiated the appropriate action (e.g., choosing the weaker doll in the wall task to move the heavy object). This suggests that the participants understood the task.
}

dren's ability to consider others' action capabilities in helping situations develops at least around 3 years of age.

In the following, we will first discuss the relation of our findings to the literature on selective social learning in preschool children. Then, we will discuss the impact of the task on children's performance, and the possible mechanisms that could subserve children's performance in the choice and the justification measure. Finally, the implications of our results for theories on the development of action perception and joint actions are considered.

Our results add to recent findings on children's selective reliance on other people in social learning tasks (e.g., Birch et al. 2008; Clement et al. 2004; Koenig and Harris 2005; Pasquini et al. 2007; Sobel and Corriveau 2010; Sodian et al. 2006). In particular, it has been found that 3- to 4year-old children monitor others' past performances and selectively learned novel object labels from the previously more accurate person (Koenig et al. 2004). Furthermore, selective learning is not restricted to language acquisition. Birch and colleagues (2008) provided evidence that preschool children also selectively relied on a previously accurate person to acquire knowledge about a novel object's function. Our results extend these findings to the realm of physical action capabilities by demonstrating that by 3.5 years of age children take physical action capabilities into account when assessing situations in which someone needs others' help.

It should be noted that we employed a third-person approach to study children's developing ability to evaluate others' physical action capabilities. Employing such an approach enabled us to examine children's performances across a number of diverse tasks that assessed different person characteristics. This allows us to rule out that the developmental trends in our results are restricted to one kind of physical action capability (e.g., strength but not height). However, even though developmental research on children's social-cognitive development has successfully used tasks that employed dolls (e.g., Fawcett and Markson 2010a) or photos (Shutts et al. 2010) to depict human actors, it would be interesting to explore the impact of different kind of tasks on children's ability to evaluate others' action capabilities. In particular, future research is necessary to investigate whether children would show earlier success in a task in which the children need to seek help for 
themselves and can choose among possible helpers whose action capabilities differ. Notwithstanding this possibility, our results point to an important developmental lag between children's ability to choose the appropriate person for help and to justify their choices.

The present finding raises the question of how this ability develops. Different mechanisms have been suggested to affect and subserve the processing of other's actions. In particular, two possible mechanisms might underlie this ability and will be discussed in the following paragraphs: motor resonance and affordance perception.

Within a motor simulation account, it has been proposed that observers use their own agentive action experiences and action capabilities to process information about other people's actions (Wilson and Knoblich 2005). Although previous research with adults and young children has provided evidence for an impact of one's own action capabilities on their action perception (e.g., Eskenazi et al. 2009; Paulus et al. 2011b), it is unlikely that this mechanism can be the main cause for children's improvement in the perception of others' action capabilities as there are no obvious motor developments around 3 years of age that could affect the perception of such different properties as strength and height or the use of one or both hands.

Alternatively, research has emphasized the role of perceptual information and especially of affordance perception in the evaluation of others' action capabilities (e.g., Mark 2007; Rochat 1995; Stoffregen et al. 1999). In particular, it has been argued that "action understanding and prediction may reflect a situated, online sensitivity to optical information, especially in the case of predicting possibilities for action" (Ramenzoni et al. 2008, p. 1060). Based on these findings, one could argue that, for example, the affordance for grasping the object on the balcony in one of our tasks was different for the tall compared with the small person. The fact that only 3.5-year-old children but not 2.5 -year-old children were able to choose the appropriate helper could thus indicate that the ability to perceive the affordances of others' actions develops around the fourth year of life. Is this a reasonable explanation given the findings within the object perception literature that already infants are able to perceive the action affordances for different objects (e.g., Paulus and Hauf 2011; Gibson and Pick 2000)? Note that our task differs from studies on infants' object perception, in that, our study did not require the perception of the actions the objects afforded for the children themselves, but rather the actions the objects afforded for another person. Furthermore, as they had to choose among two possible helpers, they had to compare the actions afforded by the objects for two different persons. Such a comparison likely demands more cognitive resources and thus develops later than the direct perception of object affordances. However, our results do not directly point to cognitive mechanism underlying children's behavior in the choice task. Further research is necessary to investigate the impact of motor resonance and affordance perception on children's perception of other people's action capabilities.

The question of the cognitive mechanisms relates also to a currently debated topic in the literature on children's selective learning (cf. Koenig and Jaswal 2011; Koenig and Woodward 2010; Lucas and Lewis 2010). It has been discussed that children's reliance on a more reliable actor in a selective social learning task might be due to a general preference for this actor (i.e., a halo effect) than due to an expectation that this actor has specific knowledge that another actor does not have (Koenig and Jaswal 2011). Applied to our study, one could ask if children's performances might be due to a diffuse knowledge that, for example, taller is better and that they therefore choose the taller doll in the balcony task. Whereas this explanation cannot be excluded for all of our tasks, a comparison of the balcony task and the dog's house task suggest that this is not the case. In particular, for both tasks, the same dolls were used (i.e., tall and small princess). Yet, in one task, the tall princess and in the other task, the small princess was the more appropriate helper. The fact that the majority of the 3.5-year-old children and all of the 5-year-old children chose the appropriate doll in each task suggests that their choices were not subserved by a general preference for the tall or the small doll, but rather by more differentiated knowledge about who was more appropriate for which task. Our findings are thus in line with findings by Koenig and Jaswal (2011) that children have a specific expectation for which knowledge domain someone is expert in by showing that they also have a specific expectation of what a person can or cannot do.

Importantly, further insight into the nature of children's developing understanding of other people's action capabilities is provided by a comparison between the choice data and the justification data. Even though the 3.5- and 5-yearolds performed at approximately the same level in terms of choices alone, our analysis revealed profound age differences in their ability to justify their choices. Justifying a correct choice means explicating implicit or practical knowledge in a discursive format (Karmiloff-Smith 1992; see also Brandom 1994), a format that is open to reflection and that allows assessment of the validity of reasons (cf. Habermas 1985; Hacker 2006). The fact that the younger children were able to adequately judge others' action capabilities without necessarily being able to justify their choice is thus not only in line with other studies showing that children's justifications lag their judgments in development (e.g., Thomas and Horton 1997; for a controversial discussion of which criteria to use in the attribution of knowledge to a child see also van der Maas et al. 2004; Smith 1992). It also supports the theoretical notion that perceiving the 
relation between an actor and the possible targets of his action has to be conceived of being practical (or implicit) knowledge that is not reflected in conceptual terms.

However, our research leaves open the question of what mechanisms subserve the developing ability to justify one's own actions. It has been argued that children's embedding in social discourses plays a fundamental role in their cognitive development (Nelson 2007; Vygotsky 1991). Support for this theoretical approach comes from studies that show relations between mothers' and their children's use of justifications in disputes (Dunn and Munn 1987) or the impact of training in exploratory talk on subsequent reasoning in school children (Wegerif et al. 1999). Accordingly, children's ability to explicate their knowledge could be promoted by their progressive embedding in discourses in which they are asked to justify their actions. However, it remains an open question whether children's developing justification abilities are due to a general development in reasoning skills (i.e., domain independent) or restricted to a particular knowledge domain (see Sodian and Bullock 2008). Furthermore, in this study, we did not control for general language or cognitive abilities. Even though our results indicate that the 3.5-year-old children were able to understand the question and to provide relevant answers, indicating that their worse performances in the justification task were not due to lacking language skills, the precise impact of children's language skills on their task performance remains an open question. Future research is necessary to directly examine the development of justification skills in preschool children. Whatever the precise developmental origin of this ability may be, our results provide clear evidence that from 5 years on, children are able to explicitly reason about another person's action capabilities when they have to decide whom to ask for help.

Our results have implications for research on children's developing action understanding and their ability to engage in successful joint actions with others. Whereas research has shown that infants from their first year of life use information about another agent's past behavior and their own action experiences to predict or understand others' actions (Paulus et al. 2011a; Sommerville and Woodward 2005), it has remained an open question how children process others' action capabilities, i.e., actionrelated information when no ongoing action is presented. Our finding that 3.5 -year-old children but not 2.5 -year-old children are able to do so indicates that having an understanding of others' action capabilities is a more complex computation (i.e., a rather abstract evaluation of what somebody could do, if he would act in a certain situation) than predicting, for example, the goal of an ongoing action. Our findings are, therefore, informative for theories on the development of social understanding (e.g., Barresi and Moore 1996).
Our results also inform current research on the development of children's developing ability to engage in successful joint actions. To effectively collaborate with other people in joint activities, one must be able to take another person's physical action capabilities into account (Sebanz et al. 2006). Our findings provide evidence that this essential social-cognitive ability for successful joint action develops around 3 years of age. Together with recent studies showing that other crucial social-cognitive abilities for the ability to engage in successful joint actions develop around 3 years of life (forming joint commitment: Gräfenhain et al. 2009; action coordination: Meyer et al. 2010), our results suggest thus that by approximately 3 years of age children have developed the necessary social-cognitive prerequisites to successfully cooperate with others.

Taken together, the present study extends current knowledge by showing that children from at least 3.5 years of age on are able to perceive others' physical action capabilities and that 5-year-olds, but not younger children are able to adequately reason about others' action capabilities.

Acknowledgments We are grateful to Beth McDougall for her support in data acquisition and Samantha Gillis for data coding. We thank Christine Fawcett for helpful discussions and two anonymous reviewers for valuable feedback on the first version of this manuscript. The first author wants to express special thanks to Harold Bekkering and the Radboud Internationalisation Fund who enabled his research stay at Dalhousie University.

Open Access This article is distributed under the terms of the Creative Commons Attribution Noncommercial License which permits any noncommercial use, distribution, and reproduction in any medium, provided the original author(s) and source are credited.

\section{References}

Baldwin DA, Moses LJ (1996) The ontogeny of social information gathering. Child Dev 67:1915-1939

Barresi J, Moore C (1996) Intentional relations and social understanding. Behav Brain Sci 19:107-122

Birch SAJ, Vauthier SA, Bloom P (2008) Three- and four-year-olds spontaneously use others' past performance to guide their learning. Cognition 107:1018-1034

Brandom RB (1994) Making it explicit. Reasoning, representing, and discursive commitment. University Press, Harvard

Clement F, Koenig MA, Harris PL (2004) The ontogenesis of trust. Mind Lang 19:360-379

Corriveau KH, Harris PL (2009) Preschoolers continue to trust a more accurate informant 1 week after exposure to accuracy information. Dev Sci 12:188-193

Dunn J, Munn P (1987) Development of justification in disputes with mother and sibling. Dev Psychol 23:791-798

Eskenazi T, Grosjean M, Humphreys GW, Knoblich G (2009) The role of motor simulation in action perception: A neuropsychological case study. Psych Res 73:477-485

Fawcett CA, Markson L (2010a) Similarity predicts liking in 3-yearold children. J Exp Child Psych 105:345-358

Fawcett CA, Markson L (2010b) Children reason about shared preferences. Dev Psych 46:299-309 
Gibson EJ, Pick AD (2000) An ecological approach to perceptual learning and development. University Press, Oxford

Gräfenhain M, Behne T, Carpenter M, Tomasello M (2009) Young children's understanding of joint commitments. Dev Psychol 45:1430-1443

Habermas J (1985) The theory of communicative action, Vol. 1: Reason and the rationalization of society. Beacon, Boston

Hacker PMS (2006) Human nature: the categorical framework. WileyBlackwell, Chichester

Jaswal VK, Neely LA (2006) Adults don't always know best: Preschoolers use past reliability over age when learning new words. Psych Sci 17:757-758

Karmiloff-Smith A (1992) Beyond modularity: A developmental perspective on cognitive science. MIT Press, Cambridge

Koenig MA, Harris PL (2005) Preschoolers mistrust ignorant and inaccurate speakers. Child Dev 76:1261-1277

Koenig MA, Jaswal VK (2011) Characterizing children's expectations about expertise and incompetence: Halo or pitchwork effects? Child Dev (in press)

Koenig MA, Woodward AL (2010) 24-month-olds' sensitivity to the prior inaccuracy of the source: Possible mechanisms. Dev Psych 46:815-826

Koenig MA, Clement F, Harris PL (2004) Trust in testimony: Children's use of true and false statements. Psych Sci 15:694-698

Lucas AJ, Lewis C (2010) Should we trust experiments on trust? Hum Dev 53:167-172

Mark LS (2007) Perceiving the actions of others. Ecol Psychol 19:107136

Marsh KL, Johnston L, Richardson MJ, Schmidt RC (2009) Toward a radically embodied, embedded social psychology. Europ J Soc Psych 39:1217-1225

Meyer M, Bekkering H, Paulus M, Hunnius S (2010) Joint action coordination in $2 \frac{1}{2}-$ and 3-year-old children. Front Hum Neurosci 4:220. doi: $10.3389 /$ fnhum. 2010.00220

Moore C (2006) The development of commonsense psychology. LEA, Mahwah

Nelson K (2007) Young minds in social worlds: Experience, meaning, and memory. University Press, Harvard

Newman RS (2000) Social influences on the development of children's adaptive help seeking: The role of parents, teachers, and peers. Dev Rev 20:350-404

Olson KR, Spelke ES (2008) Foundations of cooperation in young children. Cognition 108:222-231

Pasquini E, Corriveau KH, Koenig M, Harris PL (2007) Preschoolers monitor the relative accuracy of informants. Dev Psychol 43:1216-1226

Paulus M, Hauf P (2011) Infants' use of material properties to guide their actions with differently weighted objects. Inf Child Dev (in press). doi:10.1002/icd.704

Paulus M, Hunnius S, van Wijngaarden C, Vrins S, van Rooij I, Bekkering H (2011a) The role of frequency information and teleological reasoning in infants' and adults' action prediction. Dev Psychol (in press)

Paulus M, Hunnius S, Vissers M, Bekkering H (2011b) Imitation in infancy: Rational or motor resonance? Child Dev (in press)

Puustinen M (1998) Help-seeking behavior in a problem-solving situation: Development of self-regulation. Europ J Psych Educ 13:271-282
Rakoczy H, Warneken F, Tomasello M (2009) Young children's selective learning of rule games from reliable and unreliable models. Cogn Dev 24:61-69

Ramenzoni VC, Riley MA, Shockley K, Davis T (2008) An information-based approach to action understanding. Cogn 106:10591070

Richardson MJ, Shockley K, Fajen BR, Riley MA, Turvey MT (2008) Ecological Psychology: Six principles for an embodied-embedded approach to behavior. In: Calvo P, Gomila T (eds) Handbook of cognitive science: An embodied approach. Elsevier, Amsterdam, pp 161-197

Rochat P (1995) Perceived reachability for self and for others by 3 to 5-year old children and adults. J Exp Child Psychol 59:317-333

Sebanz N, Bekkering H, Knoblich G (2006) Joint action: bodies and minds moving together. Trends Cogn Sci 10:70-76

Shutts K, Banaji MR, Spelke ES (2010) Social categories guide young children's preferences for novel objects. Dev Sci 13:599-610

Smith L (1992) Judgments and justifications: Criteria for the attribution of children's knowledge in Piagetian research. Br J Dev Psychol 10:1-23

Sobel DM, Corriveau KH (2010) Children monitor individuals' expertise for word learning. Child Dev 81:669-679

Sodian B, Bullock M (2008) Scientific reasoning-Where are we now? Cogn Dev 23:431-434

Sodian B, Thoermer C, Dietrich N (2006) Two- to four-year-old children's differentiation of knowing and guessing in a non-verbal task. Europ J Dev Psychol 3:222-237

Sommerville JA, Woodward AL (2005) Pulling out the intentional structure of human action: The relation between action production and processing in infancy. Cognition 95:1-30

Stoffregen TA, Gorday KM, Sheng YY, Flynn SB (1999) Perceiving affordances for another person's actions. J Exp Psychol Hum Percept Perform 25:120-136

Thomas H, Horton JJ (1997) Competency criteria and the class inclusion task: Modeling judgments and justifications. Dev Psychol 33:1060-1073

Vaish A, Missana M, Tomasello M (2011) Three-year-old children intervene in third-party moral transgressions. Br J Dev Psychol (in press)

van der Maas H, Jansen B, Raijmakers M (2004) Developmental patterns in proportional reasoning. In: Demetriou A, Raftopoulos A (eds) Cognitive developmental change: Theories, models and measurement. Cambridge Studies in Cognitive and Perceptual Development, Cambridge, pp 118-156

Vygotsky L (1991) The genesis of higher mental functions. In: Light P, Sheldon S, Woodhead M (eds) Learning to think. Routledge, London, pp 34-63

Walden TA, Ogan TA (1988) The development of social referencing. Child Dev 59:1230-1240

Wegerif R, Mercer N, Dawes L (1999) From social interaction to individual reasoning: an empirical investigation of a possible socio-cultural model of cognitive development. Learn Instr 9:493-516

Wilson M, Knoblich G (2005) The case for motor involvement in perceiving conspecifics. Psychol Bull 131:460-473 